Article

\title{
Cyanobacteria and Microalgae: Thermoeconomic Considerations in Biofuel Production
}

\author{
Umberto Lucia *,+ (iD) and Giulia Grisolia + (D) \\ Dipartimento Energia “Galileo Ferraris", Politecnico di Torino, Corso Duca degli Abruzzi 24, 10129 Torino, Italy; \\ giulia.grisolia@polito.it \\ * Correspondence: umberto.lucia@polito.it; Tel.: +39-011-090-4558 \\ + These authors contributed equally to this work.
}

Received: 17 November 2017; Accepted: 4 January 2018; Published: 9 January 2018

\begin{abstract}
In thermodynamics, the useful work in any process can be evaluated by using the exergy quantity. The analyses of irreversibility are fundamental in the engineering design and in the productive processes' development in order to obtain the economic growth. Recently, the use has been improved also in the thermodynamic analysis of the socio-economic context. Consequently, the exergy lost is linked to the energy cost required to maintain the productive processes themselves. The fundamental role of the fluxes and the interaction between systems and their environment is highlighted. The equivalent wasted primary resource value for the work-hour is proposed as an indicator to support the economic considerations on the biofuel production by using biomass and bacteria. The equivalent wasted primary resource value for the work-hour is proposed as an indicator to support the economic considerations of the biofuel production by using biomass and bacteria. Moreover, the technological considerations can be developed by using the exergy inefficiency. Consequently, bacteria use can be compared with other means of biofuel production, taking into account both the technologies and the economic considerations. Cyanobacteria results as the better organism for biofuel production.
\end{abstract}

Keywords: bioenergy; biofuels; cyanobacteria; entropy; exergy; sustainability

\section{Introduction}

To date, our society continues to maintain a deep dependence upon fossil fuels as primary sources of energy, but, in the last decade, the need for decreasing the emissions of greenhouse gases has strongly emerged. For land-based transport, electric power could represent an alternative technology to heat engines, but for aviation transport and shipping, there exists no practical alternative engine in the foreseeable future. Thus, a real interest in the industrial development of liquid biofuels is emerging. Indeed, in the last decades, with reference to 1979, a fundamental improvement of 30-40\% per annum in the production of biodiesel and bioethanol from crop plants has been made [1], but these still continue to represent only less than $1 \%$ of the world's energy production: of the order of $10^{6} \mathrm{TJ}$ for bioethanol in comparison to the order of around $10^{8} \mathrm{TJ}$ for the global energy use. Moreover, this first generation of biofuels has been the subject of a great number of ethical criticisms, both in relation to the land and water use, and to their conditioning of the food commodity price, with related social consequences [2]. Consequently, a new improvement in research on new processes of biofuel production has occurred. Two different industrial processes are of interest:

- the algal biomass production;

- the use of bacteria.

Macroalgae (seaweeds) have gained a place in the market, and they are playing a growing role in biofuel production. From an energy production viewpoint, the fundamental difference between 
bacteria and eukaryotes is their subcellular structure; indeed, the major components of the cell membranes are just the high-polar phospholipids and the glycolipids, which are the fundamental components of the algal lipids, with important industrial consequences [1]. Microalgae are able to photosynthesize, and they can live in many different habitats [3].

Initially, the interest in microalgae for biofuel production was a consequence of the 1973 oil crisis, with the aim of maintaining the security of the oil supply. Thus, in 1978, the U.S. Department of Energy developed the Aquatic Species Program, which closed down in 1996 [4]. The findings highlighted that algal biofuels could be considered a potential valuable alternative to traditional biofuels, however, if the oil prices referred to are those of the 1990s. Algae produce a great variety of lipids, hydrocarbons and other complex oils, that is, polyunsaturated fatty acids [1]. Thus, research has been developed on the lipid composition from a nutritional standpoint, with a different economic impact in comparison with the biofuel market, as nutritional product algae present a high value compared with algae for crude oil. As a consequence, the production of biofuels requires a new viewpoint: production must be considered in comparison with nutraceutical and aquaculture products.

Today, a new growing sensibility in climate changes can represent this change in the following viewpoint: microalgae are considered interesting in relation to the need of mitigating $\mathrm{CO}_{2}$ release. Indeed, algal biomass can be used also as a feedstock for the production of biodiesel, hydrogen, methane and bioethanol. Its production can represent a support to remove the carbon dioxide from the flue gases of fossil fuels. The growth rates of microorganisms can be very high because the metabolism of any living system is influenced by the surface-to-volume ratio: algae are able to divide once every 1-2 days up to every $3-4 \mathrm{~h}$, under very favorable conditions. Moreover, other advantages of microalgae as a feedstock for biofuel production, in relation to other biomass sources, must be considered:

- $\quad$ there is no requirement for soil fertility;

- if marine algae are used, there is no need to draw upon supplies of freshwater.

Increasing the use of fuels from renewable biomass sources represents a fundamental opportunity both from an ecological point of view, towards a more sustainable energy system, and from an economic point of view. Recently, political and energy polices, research and technological developments have shown interest in lignocellulosic feedstocks for these biofuels [5]; indeed, lignocellulosic feedstocks represent a solution to mitigate the competition for land and water used for food production, by increasing the biomass production per unit of land area and reducing the inputs needed to grow the biomass itself $[6,7]$.

Today, the fundamental key for improving the biofuel production systems consists of developing efficient conversion technologies that are able to be economically competitive in relation to fossil fuels. The use of bacteria for lignocellulosic feedstocks could represent a possible solution. In this paper, we wish to develop a thermodynamic and thermoeconomic analysis of this process. A thermodynamic approach is introduced to understand the fundamental topics of biology, with particular interest for the following:

1. the metabolic analysis: a system-level understanding of biological systems' structures and dynamics [8], finding also a general principle to evaluate their evolution from a thermodynamic point of view [9];

2. the cell analysis: a system-level understanding of how to control the cell behavior $[10,11]$;

3. the biotechnology: a system-level approach to design biological systems [12].

Thus, the thermodynamic analysis of life can be developed by studying only the biochemical and biophysical mechanisms common in cells and organisms [13].

An engineering thermodynamic approach has been developed, and some general considerations have recently been obtained [14] using the entropy generation principle. This principle represents a global approach and allows us to obtain the stationary states for an open irreversible system. In this paper, a thermodynamic model to obtain the different terms of the entropy generation and its application to photosynthesis is developed. However, we try also to introduce an economic 
evaluation. Recently, exergy replacement cost has been suggested as a new index that would drive towards more developed policies with the aim of reducing the consumption of scarce materials with higher replacement costs [15]. However, the evaluation of the technological level of the industrial processes can be carried out also by introducing some other indicators. Indeed, every company uses different production processes with a different environmental impact (carbon emissions included); consequently, from a sustainable viewpoint, the process itself is more important than the product obtained. Thus, the analyses of the environmental impact and the countries' technological level requires new indicators, defined as a set of a quantitative measures for the evaluation of the impact of the community on its environment. Consequently we have the following [16-18]:

- The ecological indicators must be applicable to any community.

- They are aggregated, because they cannot be limited to a single individual.

- They consider only the effects of the community on its environment.

Thus, the community and the environment become two separate but interacting systems, with the following properties for the environmental indicators:

1. They are quantities evaluable by unambiguous and reproducible methods under a well-defined set of hypotheses.

2. They must be evaluated by a numeric expression in unambiguous way.

3. They must be uniquely related to intrinsic properties of the community and of their environment.

4. They must be normalized in order to compare different communities or environments.

5. They must be defined on the basis of the accepted laws of thermodynamics.

Sciubba showed the properties of some indicators [16-19]:

- Material throughput analysis (MTA) or material inventory analysis: Its basis is the measurement of the lifestyle of a community by means of the global equivalent material flow used for the related commodities' production. The approach uses disaggregated accounting of the material inputs/outputs, on the basis of the detailed knowledge of production processes. It does not involve the second law of thermodynamics;

- Embodied energy (EEn): This allows us to obtain a direct measure of the environmental impact. It evaluates the energy used to make a product, in terms of resources and work done. However, it does not involve any measure of the quality of the energy flows.

- The transformity: In the energy analysis, the fundamental assumption is that the only energy input is the solar radiation, while all other flows are related to the solar energy equivalent to the real energy used to obtain them. This evaluation is developed by means of a proper set of coefficients, the transformities. However, it does not consider any measure of the different quality of the energy flows.

In summary, exergy is a thermodynamic quantity from which it is interesting to obtain information on the useful work obtainable in any process, while, in relation to the economic growth, the analyses of irreversibility result is fundamental for the technological improvement of the productive processes. Their role in the thermodynamics analysis of the socio-economic context is also very interesting. Consequently, we aim to link the wasted exergy and the exergy cost of the productive processes, starting from the results obtained in bioengineering thermodynamics. Thus, we suggest the use of a new thermoeconomic indicator, the equivalent wasted primary resource value for the work-hour. We use this in the thermoeconomic evaluation of biofuel production by cyanobacteria and algae.

\section{Method}

In the analysis of the thermodynamic behavior of open systems, irreversible processes represent one of the fundamental topics of investigation in thermodynamics, as a result of their fundamental 
role in the design and development of the industrial devices and processes $[20,21]$. The analyses of irreversibility are the bases of the present thermodynamics, because they allow us to evaluate the dissipations by using the entropy generation [22-24].

The interaction between living systems and the environment is the basis of life [25]; this interaction occurs through energy and mass fluxes: living systems are open systems. They are characterized by life-processes, which consist of capturing exergy in exergy storage [26], in entropy exchange, and in autopoietic processes [25]. Thus, living systems have been pointed out to exist if and only if the following hold [25]:

1. There is the possibility to convert an exergy source to entropy.

2. They are in a state far from thermodynamic equilibrium.

3. They are nested, consisting of subsystems.

Consequently, life is an organizational process: it is the result of the interconnection between subsystems and supersystems; in order to continue its life, the supersystem must outflow equal or more entropy products than its subsystems generate, in order to convert the maximum amount of available exergy sources to entropy products, obtaining a hierarchical structure $[25,27]$. Thus, communication is fundamental with respect to autopoietic processes, because it is a prerequisite for obtaining stationary states [25]. Cells realize communication only by chemical reactions, which produce or consume external metabolites accumulated inside the system, and connect internal metabolites, in constant concentrations at the cells' steady states [28]. The consequence is a continuous exchange of exergy and matter through the living cells' boundaries: they are no more than far-from-equilibrium dissipative thermodynamics systems. Erwin Schrödinger highlighted that life requires a low-entropy state [29], and Ilya Prigogine [30] introduced the concept of dissipative structures for explaining the biochemical oscillations, cellular rhythms and morphogenesis. Thus, in living systems, there is an interaction between the spatial and temporal scales [9]. In living systems, the lowest and the highest levels have a continuous impact on one another, even if Krakauer et al. [9] have experimentally shown that regularities exist only at the aggregate level of description. Levin et al. [31] suggested that a fundamental issue is to understand how the different scales' signature is communicated: a hierarchical hypothesis has been introduced, on the basis of a natural selection able to minimize the power loss when resources are delivered to the cells of the body [9,32,33].

A cell with optimal performance is the result of a process of selection in its environment [34-36]: cells obtain their optimality by redistributing the flux pattern through the metabolic network, involving the pattern of catalytic and regulatory proteins; indeed, the organism can adapt to environmental conditions by realizing mutations and genetic rearrangements [37].

\subsection{Energy Content}

In 1824, Carnot introduced an ideal engine that works on a reversible cycle without dissipation. It converts the absorbed heat into work, without irreversibility. Carnot proved the following:

1. All ideal engines operating between the same two thermal reservoirs of temperature $T_{1}$ and $T_{2}$, with $T_{1}>T_{2}$, have the same ideal efficiency $\eta_{C}=1-T_{2} / T_{1}$.

2. Any other engine, operating between the same temperatures, has an efficiency $\eta$ such that it is always $\eta<\eta_{C}$.

The result consists of the existence of a definite upper limit for any conversion of the heat into kinetic energy and work [23]. To quantify irreversibility in the dissipative processes, Clausius introduced the quantity entropy, and, in 1889, Gouy and, in 1905, Stodola independently proved that the lost exergy in a process is proportional to the entropy generation. Exergy is the maximum amount of work that can be obtained by a system as it comes to equilibrium with its reference environment. Exergy is defined in relation to a reference, which is no more than the system environment [38]. It is a measure of the ability of a system to generate changes, as a result of its nonequilibrium related to the reference environment. Thus, we can point out the following [38]: 
1. The exergy of a system in complete equilibrium with its environment is null.

2. A conservation law for exergy does not exist.

3. The exergy is carried in an amount proportional to the level of disequilibrium between the system and its environment.

4. The consumption of exergy allows us to measure any loss of energy quality.

Exergy allows engineers to design systems in order to obtain the highest efficiency at the least cost under the present technology and economic and legal conditions, but also allows the taking into account of the related ethical, ecological and social consequences; indeed, it allows the following [20]:

1. taking into account the impact of the use of energy resources on the environment;

2. evaluating the more efficient use of energy resources and of the locations, types, and magnitudes of wastes and losses;

3. evaluating the real possibility of designing more efficient energy systems in order to reduce the present technical inefficiencies.

Thus, we can highlight that the cause of any natural effect is always the dynamic balances of the interactions between the systems and their environment; in particular, the decrease of the free energy of the natural systems in the least time determines their evolution [39-51].

Following the first law of thermodynamics for open systems, any energy change is expressed by the following:

1. flows of matter through the system boundary;

2. heat through the system boundary;

3. performance of work developed by or on the system.

Thus, any process, interaction, cycle, and so forth occurs in a definite time $\tau$, which is its lifetime, and, in any process or interaction during this time, the energy variation $\Delta E$ of any open system results as follows:

$$
\Delta E=\sum_{i} Q_{i}-W+\sum_{j} \int_{0}^{\tau} \dot{m}_{i}\left(h_{j}+e_{k, j}+e_{p, j}+e_{c h, j}\right) d t
$$

where $Q$ is the heat exchanged; $W$ is the work done; $m$ is the mass flow; $h$ is the specific enthalpy; $e$ is the specific energy; and the subscripts $k, p$ and $c h$ refer to kinetic, potential and chemical terms, respectively; $i$ and $j$ are related to the number of fluxes of heat and mass, respectively. The following entropy variation, $\Delta S$, of the system occurs and is related to the previous energy variation:

$$
\Delta S=\sum_{i} \frac{Q_{i}}{T_{i}}+\sum_{j} \int_{0}^{\tau} \dot{m}_{i} s_{i} d t+S_{g}
$$

where $T$ is the temperature of any $i$ th reservoir, $s$ is the specific entropy and $S_{g}=W_{\lambda} / T_{0}$ is the entropy variation due to irreversibility, named entropy generation [39-47]; $W_{\lambda}$ is the work lost.

Combining these equations, the following exergy balance can be obtained [47]:

$$
W_{t}=\Delta B+\sum_{\alpha} J_{e x, \alpha}+\sum_{\beta} E x_{Q, \beta}-T_{0} S_{g}
$$

where we have the following:

- $W_{t}$ is the net work done during the process;

- $\Delta B=E+p_{0} V-T_{0} S$ is the accumulation of nonflow exergy;

- $J_{e x}=\int_{0}^{\tau} \dot{m}\left(e-T_{0} s\right) d t$ is the flow exergy due to mass flow;

- $E x_{Q}=Q\left(1-T_{0} / T\right)$ is the exergy transfer due to heat transfer. 
The subscript 0 refers to the environment, while $p$ is the pressure and $V$ is the volume. The work lost, $W_{\lambda}$, can be obtained as follows [45]:

$$
W_{\lambda}=\frac{E x_{\text {in }}-E x_{\text {out }}-W}{T_{0}}
$$

where Ex refers to exergy and in and out refer to inflow and outflow, respectively. Thus, the final relation useful for our analysis becomes the following:

$$
\begin{aligned}
T_{0} S_{g} & =\sum_{j} \int_{0}^{\tau} \dot{m}_{i}\left(h_{j}+e_{k, j}+e_{p, j}+e_{c h, j}\right) d t+\sum_{\ell} \int_{0}^{\tau} \dot{n}_{\ell} v_{\ell}\left(g_{\ell}^{\oplus}-e x_{c h, \ell}^{\oplus}\right) d t \\
& -\sum_{i}\left(1-\frac{T_{0}}{T}\right) Q-W_{t}-\int_{0}^{\tau} \frac{d}{d t}\left(E-T_{0} S\right) d t
\end{aligned}
$$

where $g$ is the molar specific Gibbs potential, ex $c=y\left(\mu-\mu_{0}\right)_{T_{0}, p_{0}}$ is the molar specific chemical exergy at the reference atmosphere, $y$ is the molar fraction, $\dot{n}$ is the molar flux, $v$ is the stoichiometric coefficient, and $\mu$ is the chemical potential; $\oplus$ refers to the standard conditions.

In relation to a living system, it is possible to state the following for a living system $[14,25]$ :

1. It is open, because of energy and mass flows through its boundaries.

2. It is far from equilibrium, as a result of being the source of high exergy values and basic materials.

3. It has a continuous communication, because of its information channels between its different components.

4. It is on autopoietic pathways, as a result of the existence of continuous cycles for generation and autocatalytic feedbacks.

5. It has exergy enhancement or maintenance, as a result of its entropy products fluxes, equal to or greater than the entropy production of the ingested free energy source, with an ability of decreasing its internal entropy.

6. It presents material conservation and maintains its physical components, as a result of the ability to maintain its structural basis for storing the acquired organizational exergy.

In order to state the entropy generation principle for living systems, its physical fundamentals [14] can be summarized as follows:

1. We must consider an open, irreversible, real nonlinear system, with a nonlinear response.

2. Each process has a finite lifetime $\tau$.

3. What happens in the range $[0, \tau]$ is unknown, while it is well known what has happened after the process lifetime $\tau$.

4. The entropy balance equations are a balance of fluxes of entropy and energy.

Moreover, the Gouy-Stodola principle works for real systems, and it has been used by Stodola in designing real machineries; consequently, the fundamental engineering principle is the Gouy-Stodola principle [52-54].

The sources of any physical process are the exergy gradients [54], while entropy generation describes its irreversibility [52]. Living systems are a chemical engine in which biochemical reactions occur. The causes of irreversibility [55-62] must be pointed out to evaluate the entropy generation; they are the following:

1. The thermal flux due to the temperature gradient, which provides the following component:

$$
S_{g, t f}=\int_{0}^{\tau_{1}} d t \int_{V} d V \mathbf{J}_{q} \cdot \nabla\left(\frac{1}{T}\right)=-\int_{0}^{\tau_{1}} d t \int_{V} d V \frac{\mathbf{J}_{q}}{T^{2}} \cdot \nabla T
$$

where $S_{g, t f}$ is the entropy generation component due to this phenomenon, $t$ is the time, $\tau_{1}$ is the lifetime of this process, $V$ is the volume of the living systems, $\mathbf{J}_{q}$ is the heat flux and $T$ is 
the temperature. For example, for a cell [57-62], considering that $\mathbf{J}_{q}=v_{t h} U$, with $v_{t h}$ being the molecular thermal velocity and $U$ being the cell's internal energy, the entropy generation $S_{g, t f}$ becomes

$$
S_{g, t f} \approx \frac{U v_{t h}}{T^{2}} \frac{\delta T}{L}
$$

with $L$ being the typical length of a cell, which can be evaluated as its diameter [57-63]. For example, for a normal cell, $\delta T=0$, while for a cancer cell, its maximum value is about $0.4{ }^{\circ} \mathrm{C}$ [57-62], and the entropy generation due to thermal processes can be evaluated by Equation (7); this quantity allows us to obtain information on the different behavior of a cell.

2. The diffusion current due to the chemical potential gradient, which provides the following component:

$$
S_{g, d c}=-\int_{0}^{\tau_{2}} d t \int_{V} d V \sum_{i} \mathbf{J}_{i} \cdot \nabla\left(\frac{\mu_{i}}{T}\right)
$$

where $\tau_{2}$ is the lifetime of this process, $\mu_{i}$ is the chemical potential of the $i$ th species, $\mathbf{J}_{i}=\rho_{i}\left(\mathbf{v}_{i}-\mathbf{v}_{C M}\right)$ is the diffusion flow of the $i$ th component, $\rho_{i}$ is the concentration in the living system, $\mathbf{v}_{i}$ is its velocity and $\mathbf{v}_{C M}=\sum_{i} \rho_{i} \mathbf{v}_{i} / \rho$ is the velocity of the cell's fluid center of mass, with $\rho$ being the total density. For example, for a cell [57-62], $\mathbf{J} \approx \bar{\rho} \mathbf{v}_{t h}$, with $\bar{\rho}$ being the mean concentration, and $\nabla(\mu / T) \approx \bar{\mu} / L$, with $\bar{\mu}$ being the mean value of the chemical potential. This entropy generation component becomes

$$
S_{g, d c} \approx \frac{\bar{\mu} \bar{\rho} v_{t h}}{d_{m}} \frac{V_{m}}{T}
$$

where $V_{m}$ and $d_{m}$ are the membrane volume and depth, for which the chemical potential gradient occurs particularly in the cytoplasm [57-62].

3. The velocity gradient coupled with viscous stress, which provides the following component:

$$
S_{g, v g}=-\int_{0}^{\tau_{3}} d t \int_{V} d V \sum_{i j} \frac{\partial_{i} v_{j} \Pi_{j i}}{T}
$$

where $\tau_{3}$ is the lifetime of this process and $\Pi_{j i}$ is the stress tensor. For example, in a cell [57-62], this can be evaluated as

$$
S_{g, v g} \approx \frac{4 \pi}{T d_{e}} \bar{\eta}\left(v_{C M} \bar{r}\right)^{2}
$$

where $d_{e}$ is the cytoplasm layer and $\bar{r}$ is the mean cell radius.

4. The chemical reaction rate due to affinity, which provides the following component:

$$
S_{g, c r}=\int_{0}^{\tau_{4}} d t \int_{V} d V \sum_{n} N_{n} \frac{\Delta G_{n}^{0}}{T}
$$

where $\tau_{4}$ is the lifetime of this process, $N$ is the number of the $n$th reaction and $\Delta G^{0}$ is the affinity, evaluated as the variation of the standard Gibbs function. For example, for a cell [57-63], the proteolytic and lipolytic processes, as catabolic reactions, increase the entropy generation; thus, in cancer cells, this component is greater than in normal cells. This thermodynamic approach allows us to obtain information on the different behavior of the different kinds of cell systems.

5. The dissipation due to work for interactions with an external field in the environment, which provides the following component:

$$
S_{g, d e}=\int_{0}^{\tau_{5}} d r \int_{V} d V \sum_{k} \frac{\mathbf{J}_{k} \cdot \mathbf{F}_{k}}{T}
$$

where $\tau_{5}$ is the lifetime of this process, $F$ is the force generated by the interaction with the external field and $J$ is the associated flux. 
Consequently, the entropy generation of a living system is

$$
S_{g}=S_{g, t f}+S_{g, d c}+S_{g, v g}+S_{g, c r}+S_{g, d e}
$$

From the previous considerations, it must be pointed out that entropy generation allows us to describe the stationary states of living systems, from an engineering thermodynamic approach, while it also allows us to evaluate the normal or diseased state for cells or organisms. Consequently, it is a fundamental quantity, useful both for engineering applications of living structures, as bacteria use in fermentation and so forth, and in biological or medical studies of the evolution of diseases.

Photosynthesis is a process that leads to complex organic molecules starting from simple molecules and by absorbing solar radiation $[64,65]$. We consider the following chemical reactions for superior plants and bacteria [64]:

$$
6 \mathrm{CO}_{2}+6 \mathrm{H}_{2} \mathrm{O} \rightarrow \mathrm{C}_{6} \mathrm{H}_{12} \mathrm{O}_{6}+6 \mathrm{O}_{2}
$$

Other reactions are undergone by the following:

1. Superior plants and cyanobacteria:

$$
6 \mathrm{CO}_{2}+12 \mathrm{H}_{2} \mathrm{O} \rightarrow \mathrm{C}_{6} \mathrm{H}_{12} \mathrm{O}_{6}+6 \mathrm{H}_{2} \mathrm{O}+6 \mathrm{O}_{2}
$$

2. Sulfur purple bacteria, sulfur green bacteria and young bacteria:

$$
6 \mathrm{CO}_{2}+12 \mathrm{H}_{2} \mathrm{~S} \rightarrow \mathrm{C}_{6} \mathrm{H}_{12} \mathrm{O}_{6}+6 \mathrm{H}_{2} \mathrm{O}+12 \mathrm{~S}
$$

3. Sulfur purple bacteria and old bacteria:

$$
6 \mathrm{CO}_{2}+6 \mathrm{H}_{2} \mathrm{O}+3 \mathrm{H}_{2} \mathrm{~S} \rightarrow \mathrm{C}_{6} \mathrm{H}_{12} \mathrm{O}_{6}+3 \mathrm{H}_{2} \mathrm{SO}_{4}
$$

4. Sulfur purple bacteria and sulfur green bacteria:

$$
6 \mathrm{CO}_{2}+15 \mathrm{H}_{2} \mathrm{O}+3 \mathrm{Na}_{2} \mathrm{~S}_{2} \mathrm{O}_{3} \rightarrow \mathrm{C}_{6} \mathrm{H}_{12} \mathrm{O}_{6}+6 \mathrm{H}_{2} \mathrm{O}+6 \mathrm{NaHSO}_{4}
$$

5. Nonsulfur purple bacteria and nonsulfur green bacteria:

$$
6 \mathrm{CO}_{2}+12 \mathrm{CH}_{3} \mathrm{CH}_{2} \mathrm{OH} \rightarrow \mathrm{C}_{6} \mathrm{H}_{12} \mathrm{O}_{6}+12 \mathrm{CH}_{3} \mathrm{CH}=+6 \mathrm{H}_{2} \mathrm{O}
$$

6. Nonsulfur purple bacteria and nonsulfur green bacteria:

$$
2 \mathrm{CO}_{2}+4 \mathrm{CH}_{3} \mathrm{OH} \rightarrow \mathrm{C}_{6} \mathrm{H}_{12} \mathrm{O}_{6}+2 \mathrm{H}_{2} \mathrm{O}
$$

7. Nonsulfur purple bacteria:

$$
6 \mathrm{CO}_{2}+12 \text { Succinic acid } \rightarrow \mathrm{C}_{6} \mathrm{H}_{12} \mathrm{O}_{6}+12 \text { Fumaric acid }
$$

8. Nonsulfur purple bacteria:

$$
6 \mathrm{CO}_{2}+12 \text { Malic acid } \rightarrow \mathrm{C}_{6} \mathrm{H}_{12} \mathrm{O}_{6}+12 \mathrm{Oxalacetic} \mathrm{acid}
$$

9. Heliobacteria:

$$
\begin{array}{r}
3 \mathrm{CH}_{3} \mathrm{COOH}+6 \mathrm{H}_{2} \mathrm{O} \rightarrow 6 \mathrm{CO}_{2}+12 \mathrm{H}_{2} \\
6 \mathrm{CO}_{2}+12 \mathrm{H}_{2} \rightarrow \mathrm{C}_{6} \mathrm{H}_{12} \mathrm{O}_{6}+6 \mathrm{H}_{2} \mathrm{O}
\end{array}
$$

Now, it is fundamental to evaluate the entropy generation, to introduce the entropy generation principle in the thermodynamic analysis of photosynthesis. We consider the sun, the photosynthetic organism and the earth as different systems [64]. Fluxes occur among these. The process under study can be analyzed in four steps: 
1. Light comes from sun to the photosynthetic organism without any work carrying an energy (and exergy) flux. The sun emits a gas of photons, which follows an adiabatic expansion, with a related dilution of photons, along the path from the sun to the earth. Consequently, the sun can be considered as a grey-body at temperature $T_{S}=5762 \mathrm{~K}$ in radiative equilibrium with the earth. The earth absorbs all the radiation; consequently, it behaves as a black-body at atmospheric temperature $T_{E}=298.15 \mathrm{~K}$. The first law holds:

$$
\begin{aligned}
\varepsilon \sigma T_{S}^{4} & =\sigma T_{E}^{4} \\
\varepsilon & =\frac{R_{S}^{2}}{R_{O}^{2}}
\end{aligned}
$$

with $\sigma=5.67 \times 10^{-8} \mathrm{Wm}^{-2} \mathrm{~K}^{-4}, \epsilon$ being the emissivity, $R_{S}$ being the sun's radius and $R_{O}$ being the earth's radius. The entropy generation during the process can be evaluated as follows [64]:

$$
S_{g, S E}=\frac{4}{3} 60 N_{A} h v\left(\frac{1}{T_{E}}-\frac{1}{T_{S}}\right)
$$

with $v=c / \lambda$ being the frequency, $c$ being the light velocity, $\lambda$ being the wavelength, $h=6.626 \times 10^{-32}$ Js being the Planck's constant and with $N_{A}=6.022 \times 10^{23} \mathrm{~mol}^{-1}$.

2. The photosynthetic organism absorbs the light from its environment, and the entropy generation results in $S_{g, l a}=0 \mathrm{~J} \mathrm{~K}^{-1}$, because this happens at a constant temperature $\left(T_{P O}=T_{E}\right.$, where $P O$ refers to the photosynthetic organism) without any work.

3. Glucose is produced by the photosynthetic organism by using the exergy absorbed from the light, and the related entropy generation results in

$$
S_{g, g p}=-\frac{\Delta G_{P O}}{T_{P O}}
$$

where $P O$ refers to the photosynthetic organism.

4. The remaining heat is exchanged by the photosynthetic organism with the earth, with the related entropy generation being $S_{g, P O E}=0 \mathrm{~J} \mathrm{~K}^{-1}$, because this happens at the same temperature without any work.

In summary, the entropy generation for the photosynthesis process results in

$$
S_{g, P S}=S_{g, S E}+S_{g, l a}+S_{g, g p}+S_{g, P O E}=\frac{4}{3} 60 N_{A} h v\left(\frac{1}{T_{E}}-\frac{1}{T_{S}}\right)-\frac{\Delta G_{P O}}{T_{P O}}
$$

The consequent reaction efficiency can be evaluated as

$$
\eta=\frac{\Delta G^{0}}{60 N_{A} h v}
$$

For the above nine chemical reactions, the entropy generation is evaluated in Table 1 . It can be pointed out that from an engineering approach, the superior plants have the higher efficiency.

This last relation allows us to evaluate all the dissipations during the process, and to introduce a new indicator, the exergy inefficiency, which allows us to measure the technological level of a process in relation to the unavailability $[20,21]$ :

$$
\varepsilon_{\lambda}=\frac{T_{0} S_{g}}{E x_{i n}}
$$

This quantity measures the technological maturity of a production system or a production sector in a country, because it quantifies just the effect of the process losses. The lower the value of the exergy inefficiency, the more the industrial process is efficient in terms of energy use $[20,21,66]$. 
Table 1. Entropy generation and efficiency for photosynthesis in relation to 1 mol $_{\mathrm{C}_{6}} \mathrm{H}_{12} \mathrm{O}_{6}$ produced (data summarized in [64]).

\begin{tabular}{|c|c|c|c|c|}
\hline $\begin{array}{c}\lambda \\
(\mathrm{nm})\end{array}$ & $\begin{array}{l}\text { Reaction } \\
\text { Equation }\end{array}$ & $\begin{array}{c}\Delta G^{0} \\
\left(\mathrm{~kJ} \mathrm{~mol}^{-1}\right)\end{array}$ & $\begin{array}{c}\Delta s_{g, P S} \\
\left(\mathrm{~kJ} \mathrm{~mol}^{-1} \mathrm{~K}^{-1}\right)\end{array}$ & $\begin{array}{c}\eta \\
\%\end{array}$ \\
\hline 680 & (16) & 2880.31 & 37.543 & 27.288 \\
\hline 798 & (24) & 320.65 & 39.148 & 3.565 \\
\hline \multirow{4}{*}{840} & (17) & 429.64 & 36.771 & 5.028 \\
\hline & (19) & 621.47 & 36.128 & 7.273 \\
\hline & (20) & 584.86 & 36.251 & 6.845 \\
\hline & (21) & 71.27 & 37.973 & 0.834 \\
\hline \multirow{7}{*}{870} & (17) & 429.64 & 35.454 & 5.208 \\
\hline & (18) & 744.57 & 34.397 & 9.025 \\
\hline & (19) & 621.47 & 34.810 & 7.533 \\
\hline & (20) & 584.86 & 34.933 & 7.089 \\
\hline & (21) & 71.27 & 33.197 & 0.864 \\
\hline & (22) & 1066.56 & 33.137 & 12.928 \\
\hline & (23) & 609.48 & 34.850 & 7.388 \\
\hline \multirow{3}{*}{890} & (17) & 429.64 & 34.625 & 5.327 \\
\hline & (18) & 744.57 & 33.568 & 9.232 \\
\hline & (19) & 621.47 & 33.981 & 7.706 \\
\hline \multirow{4}{*}{960} & (20) & 584.86 & 31.474 & 7.822 \\
\hline & (21) & 71.27 & 33.197 & 0.953 \\
\hline & (22) & 1066.56 & 29.859 & 14.265 \\
\hline & (23) & 609.48 & 31.392 & 8.152 \\
\hline
\end{tabular}

\subsection{Cost Production}

Starting from the thermodynamic results, we can also define the sustainability of a process by using a new indicator, the equivalent wasted primary resource value for the work-hour, defined as

$$
E I_{\lambda}=\frac{T_{0} S_{g}}{n_{h} n_{w}}
$$

where $n_{h}$ is the working hours and $n_{w}$ is the number of workers. This quantity allows us to quantify the cost of the wasted exergy required for the support of the work-hours and for capital flow generation.

Thermodynamic and thermoeconomic analyses, in particular, the second law analysis, represent a powerful approach to evaluate the technological option for technology selection in order to design more efficient biofuel production systems. In order to show the use of the approach suggested here, we compare the following, with the aim to develop thermoeconomic considerations of the biomass obtained:

- the cyanobacterium Arthrospira platensis, known as Spirulina platensis;

- the microalga Chlorella vulgaris.

The properties of these biosystems are summarized in Table 2. We have no data on a possible number of workers and work-hours for an industrial use of these biosystems; thus, in order to develop our evaluation, we modify the previous relation (Equation (31)) as follows:

$$
E I_{\lambda}=\frac{T_{0} s_{g, P S}}{\dot{m}_{\mathrm{CO}_{2}} \dot{m}_{\mathrm{C}_{6} \mathrm{H}_{12} \mathrm{O}_{6}}}
$$

where $\dot{m}_{\mathrm{C}_{6} \mathrm{H}_{12} \mathrm{O}_{6}}$ represents the biomass produced in a day and $n_{\mathrm{CO}_{2}}$ is the moles of $\mathrm{CO}_{2}$ used by the biosystem. The two biosystems have the same metabolic properties, represented by the chemical 
Equation (16). The temperature $T_{0}$ considered is the temperature of water in their photobioreactor, $30{ }^{\circ} \mathrm{C}(=300.15 \mathrm{~K})$.

Table 2. Data for numerical evaluation $[67,68]$.

\begin{tabular}{|c|c|c|c|c|}
\hline Biosystem & $\begin{array}{l}\text { Biomass Content } \\
\text { \% Dry Weight }\end{array}$ & $\begin{array}{l}\text { Biomass Produced } \\
\left(10^{-3} \mathrm{~kg} \mathrm{~m}^{-3} \mathrm{~d}^{-1}\right)\end{array}$ & $\begin{array}{c}\mathrm{CO}_{2} \text { Fixed } \\
\left(10^{-3} \mathrm{~kg} \mathrm{~m}^{-3} \mathrm{~d}^{-1}\right)\end{array}$ & $\underset{\%}{\mathrm{CO}_{2}} \underset{\%}{\text { Supply }}$ \\
\hline Spirulina platensis & $5.0-58.0$ & 2.91 & 318.61 & 10 \\
\hline Chlorella vulgaris & $4.0-16-6$ & 2.25 & 251.64 & 10 \\
\hline
\end{tabular}

The results obtained can be summarized as follows:

- for Spirulina platensis: $2187 \mathrm{MJ} \mathrm{kg}_{b}^{-1}=607.5 \mathrm{kWh} \mathrm{kg}_{b}^{-1}$;

- for Chlorella vulgaris: $3581 \mathrm{MJ} \mathrm{kg}_{b}^{-1}=994.7 \mathrm{kWh} \mathrm{kg}_{b}^{-1}$.

Here, the indicator $E I_{\lambda}$ is expressed in kilowatt-hours in order to assign an economic value comparable with other energy resources. The result is expressed in energy consumed per unit mass of biomass produced. In particular, considering the mean value of the kilowatt-hour mean cost in EURO-area as $0.220 \mathrm{EUR} \mathrm{kWh}^{-1}$ [69], we can obtain the following cost of production:

- $\quad$ for Spirulina platensis: $133.65 \mathrm{EUR} \mathrm{kg}_{b}^{-1}$;

- for Chlorella vulgaris: $218.83 \mathrm{EUR} \mathrm{kg}_{b}^{-1}$.

\section{Results}

Today, growth is considered an imperative. In relation to the possible link between energy and economic development, the role of development has been highlighted in relation to the energy use, but it has never been highlighted that the energy use affects development [70], even if the fundamental role of energy in the promotion of the economic growth is clear [71], because energy is an essential factor of production as a result of the energy needs of all the economic processes. However, the economic analyses of growth are usually focused only on capital and labor.

In industrialized countries, one of the principal problems is the management of $\mathrm{CO}_{2}$ emissions. The improvement of the energy efficiency and the rational use of energy represent an economic strategy for the sustainable development in the European Union (EU) countries.

Thus, we introduce new indicators related to the inefficiency of any process and to the equivalent primary wasted resource value, to evaluate the technological level and the advanced level of industrial processes. These indicators allow us to link the exergy cost to the inefficiency of the system, allowing us to consider the cost of the wasted exergy required to maintain a process.

Carbon dioxide emissions are affected by a great number of factors, such as economic growth levels, technological development, and production process. On the other hand, the $\mathrm{CO}_{2}$ emission problem could represent an opportunity for a new design of conventional plants based on high-efficiency and related technological improvements.

In Table 3, the lipid class distribution is summarized. Triglycerides, a storage lipid, may increase if the metabolic rate slows down. Consequently, the lipid composition changes during the different phases of growth. The cyanobacteria (prokaryotic algae) contain less total lipid content than the eukaryotic algae. The former is likely because the prokaryotes do not have internal membranes. Thus, the cyanobacteria's potential as lipid producers does not appear to be promising, even if they are interesting for their easy structure because of their simple DNA, which characterizes them as easier organisms for any industrial genetic manipulation. 
Table 3. Mean lipid content as a percentage of total lipids [1,72].

\begin{tabular}{cccc}
\hline Algae Species & Simple Lipids & Glycolipids & Phospholipids \\
\hline Chaetoceros sp. & $37-16$ & $36-8$ & $25-8$ \\
Phaeodactylum tricornutum & $54-6$ & $34-5$ & $11-1$ \\
Chlamydomonas sp. & $48-10$ & $44-13$ & $6-3$ \\
Dunaliella tertiolecta & $7-1$ & $67-1$ & $25-0$ \\
Dunalliella viridis & $13-1$ & $44-3$ & $42-2$ \\
Nannochloropsis oculata & $22-1$ & $39-0$ & $38-1$ \\
Isochrysis species & $36-3$ & $35-1$ & $27-3$ \\
\hline
\end{tabular}

In fuel production, the high concentration of unsaturated fatty acids is very important because it is a characteristic of the resultant fuel quality. In algae, the unsaturated fatty acid needs seldom to be hydrogenated in order to improve the fuel properties, because the unsaturated fatty acid increases the polymerization in the engine oil with related problems to the oxidative stability of the fuel.

Lignocellulosic biorefinery is based on a biochemical conversion platform in which the conversion of the polysaccharides into fuel is obtained by using enzymes [73]. One of the principal difficulties in lignocellulosic biorefinery is the energy needs required by the process of fuel production [74-76]. Current integrated biorefinery involves lignin-enriched residue as fuel for the energy needs, with the consequence of reducing the possibility of the higher-value use of lignin. The use of external sources of low-enthalpy heat can represent a way to overcome this unwanted consequence: waste heat from fermentation due to the presence of metabolism could be one of these sources.

The results obtained highlight that biofuel becomes interesting from a sustainable point of view if obtained from cyanobacteria; indeed, by using Spyrulina platensis, the cost for the biofuel production unit mass is lower than that obtained by using Chlorella vulgaris, taking also into account the fixed amount of $\mathrm{CO}_{2}$. Moreover, the result obtained must be compared with that evaluated for the crude oil extraction. For example, we consider the steam injection for thermal enhanced oil recovery: it requires 1990-2330 MJ m${ }^{-3}$. Using the same approach to evaluate the cost in EUR $\mathrm{kWh}^{-1}$, and considering the mean value of the energy required $\left(2160 \mathrm{MJ} \mathrm{m}^{-3}=600 \mathrm{kWh} \mathrm{m}^{-3}\right)$, we obtain the cost of $132.00 \mathrm{EUR} \mathrm{m}^{-3}$ for the crude oil extract [77].

\section{Discussion}

The management of $\mathrm{CO}_{2}$ emissions represents a fundamental problem in industrialized countries. The improvement of energy efficiency and the introduction of a rational use of energy in all the EU member states could represent the economic strategy for the sustainable development in EU countries.

The potential thermodynamic improvements has been evaluated at around $80 \%$, even if only $50 \%$ of the energy can be saved by technical means, and it is reduced by $30 \%$ by the economic barriers [78,79].

In this context, the energetic and economic value of the algal biomass is determined by its composition of lipids, carbohydrates, and proteins. We can develop some considerations of their elemental composition and of their energetic properties in relation to any principal biochemical class of molecules, in particular, the following [1]:

- Carbohydrates, both monomers and polymers, are contained with a wide variety inside the microorganisms, which use them both for structural and for metabolic functions. Microorganisms obtain these as the early products of photosynthesis and as the primary source for the synthesis of other biochemical molecules. Different kinds of algae produce different specific kinds of polysaccharides.

- Proteins represent the prime catalysts for cell metabolism, with the consequence of being fundamental for the microorganisms' growth. Moreover, they play a structural role in particular as the scaffold for the assembly of the chlorophyll molecules in the light harvesting complexes of the chloroplast. 
- Nucleic acids, RNA and DNA, supported by proteins and their monomers, represent the basis for algal division and growth. They represent a small fraction of cellular biomass but are the first source of the cells' phosphate and the second source of nitrogen.

- Lipids play functions both as energy reserves and structural components in membranes (mainly phospholipids and glycolipids). Indeed, the simple fatty acid triglycerides represent a fundamental reserve of energy. The microalgae can rapidly adapt to environment changes in temperature, by maintaining the membrane characteristics, through their ability of synthesizing and recycling fatty acids. Indeed, the majority of the unsaturated fatty acids occur in the membrane lipids, in order to maintain membrane fluidity under different conditions.

Thermodynamic and thermoeconomic analyses, in particular, the second law analysis, represent a powerful approach to evaluate the technological option for technology selection in order to design more efficient biofuel production systems.

\section{Conclusions}

Biofuels are considered one of the keys for a sustainable, economical and environmentally safe source of energy. In this context, new potential improvements of the present biofuel production can be offered by microbes. However, on this topic, some questions have been addressed [80]:

- What energy resource platform could be used to make biofuels?

- What type of biofuel is the ideal fuel molecule that should be targeted?

- What microbial system could be used to produce targeted biofuel molecules?

This paper proposes a thermodynamic approach to evaluate the last question, including a new thermoeconomic evaluation based on bioeconomics.

Some plants are very efficient in the conversion of solar energy into chemical energy (reduced hydrocarbons or oils) by the process of photosynthesis, but microalgae produce oils useful for the production of a variety of biofuels and without any ethical consequences. Nowadays, microalgae are considered the highest potential triacyglycerol resource because of the high oil content and faster growth. Moreover, cyanobacteria are attractive, because they link together the favorable characteristics of prokaryotics and plants. Cyanobacteria are more efficient to convert solar energy and carbon dioxide into biofuels [80]; their genetic engineering platform is well established and they have been shown to be highly tolerant to the introduction of foreign genes. Biomass transformation into biofuel can be realized by chemical or biological conversion or their combination, but these need low fiscal and environmental costs.

These considerations highlight that new technical and energy policies are required in order to solve the ecological consequences of the power production by thermal conversions. This paper aims to suggest a new approach to support decisions on power production topics from an ecological and economic point of view.

Acknowledgments: All sources of funding of the study should be disclosed. Please clearly indicate grants that you have received in support of your research work. Clearly state if you received funds for covering the costs to publish in open access.

Author Contributions: These authors contributed equally to this work.

Conflicts of Interest: The authors declare no conflict of interest.

\section{References}

1. Le B.; Williams, P.J.; Laurens, L.M.L. Microalgae as biodiesel \& biomass feedstocks: Review \& analysis of the biochemistry, energetics \& economics. Energy Environ. Sci. 2010, 3, 554-590.

2. Gallagher, E. The Gallagher Review of the Indirect Effects of Biofuels Production; Renewable Fuels Agency: London, UK, 2008.

3. Falkowski, P.G.; Raven, J.A. Aquatic Photosynthesis; Princeton University Press: Princeton, NJ, USA, 2007. 
4. Sheehan, J.; Dunahay, T.; Benemann, J.R.; Roessler, P. A Look Back at the U.S. Department of Energy's Aquatic Species Program Biodiesel from Algae; National Renewable Energy Laboratory: Golden, CO, USA, 1998.

5. Sohel, M.I.; Jack, M.W. Thermodynamic analysis and potential efficiency improvements of a biochemical process for lignocellulosic biofuel production. In Proceedings of the Bioenergy Technology, World Renewable Energy Congress, Linköping, Sweden, 8-13 May 2011; pp. 500-507.

6. Schmer, M.R.; Vogel, K.P.; Mitchell, R.B.; Perrin, R.K. Net energy of cellulosic ethanol from switchgrass. Proc. Natl. Acad. Sci. USA 2008, 105, 464-469.

7. Tilman, D.; Socolow, R.; Foley, J.A.; Hill, J.; Larson, E.; Lynd, L.; Pacala, S.; Reilly, J.; Searchinger, T.; Somerville, C.; et al. Beneficial biofuels-The food, energy, and environment trilemma. Science 2009, $325,270-271$.

8. Kernevez, J.P.; Thomas, D. Numerical analysis and control of some biochemical systems. J. Appl. Math. Optim. 1975, 1, 237-285.

9. Krakauer, D.C.; Collins, J.P.; Erwin, D.; Flack, J.C.; Fontana, W.; Laubichler, M.D.; Prohaska, J.; West, G.B.; Stadler, P.F. The challenges and scope of theoretical biology. J. Theor. Biol. 2011, 276, 269-276.

10. Bailey, J.E. Lessons from metabolic engineering for functional genomics and drug discovery. Nat. Biotechnol. 1999, 17, 616-618.

11. Friboulet, A.; Thomas, D. System Biology-An interdisciplinary approach. Biosens. Bioelectron. 2005, 17, 2404-2407.

12. Bailey, J.E. Towards a science of metabolic engineering. Science 1991, 252, 1668-1674.

13. Carroll, S.B. Endless forms: The evolution of gene regulation and morphological diversity. Cell 2000, 101, 577-580.

14. Lucia, U. Irreversibility in biophysical and biochemical engineering. Physics A 2012, 391, 5997-6007.

15. Valero, A.; Valero, A.; Calvo, G. Using thermodynamics to improve the resource efficiency indicator GDP/DMC. Resour. Conserv. Recycl. 2015, 94, 110-117.

16. Sciubba, E. Exergy-based ecological indicators: A necessary tools for resource use assessment studies. Termotechnica 2009, 2, 11-15.

17. Sciubba, E.; Bastionani, S.; Tiezzi, E. Energy and Extended Exergy Accounting of Very Large Complex System with an Apllication to the Province of Siena. Int. J. Environ. Manag. 2008, 86, 372-382.

18. Sciubba, E. From engineering economics to extended exergy accounting: A possible path from monetary to resource based costing. J. Ind. Ecol. 2004, 8, 19-40.

19. Lucia, U. The Wasted Primary Resource Value: An Indicator for the Thermodynamics of Sustainability for Municipalities Policy. Int. J. Thermodyn. 2017, 20, 166-172.

20. Lucia, U. Econophysics and bio-chemical engineering thermodynamics: The exergetic analysis of a municipality. Physics A 2016, 462, 421-430.

21. Lucia, U.; Grisolia, G. Unavailability percentage as energy planning and economic choice parameter. Renew. Sustain. Energy Rev. 2017, 75, 197-204.

22. Lucia, U. Stationary open systems: A brief review on contemporary theories on irreversibility. Physics A 2013, 392, 1051-1062.

23. Lucia, U. Carnot efficiency: Why? Physics A 2013, 392, 3513-3517.

24. Lucia, U. Entropy generation in technical physics. Kuwait J. Sci. Eng. 2012, 39, 91-101.

25. Günther, F.; Folke, C. Characteristics of nested living systems. J. Biol. Syst. 1993, 1, 257-274.

26. Jörgensen, S.E.; Meijer, H. A holistic approach to ecological modelling. Ecol. Model. 1979, 7, 169-189.

27. Brooks, D.; Collier, J.; Maurer, B.A.; Smith, J.D.H.; Wiley, E.O. Entropy and information in evolving biological systems. Biol. Philos. 1989, 4, 407-432.

28. Srienc, F.; Unrean, P. A Statistical Thermodynamical Interpretation of Metabolism. Entropy 2010, 12, 1921-1935.

29. Schrodinger, E. What Is Life? Physical Aspects of Living Cells; Cambridge University Press: Cambridge, UK, 2006.

30. Prigogine, I.; Lefever, R.; Goldbeter, A.; Herschkowitz-Kaugman, M. Symmetry breaking instabilities in biological systems. Nature 1969, 223, 913-916.

31. Levin, S.A.; Grenfell, B.; Hastings, A.; Perelson, A.S. Mathematical and computational challenges in population biology and ecosystems science. Science 1997, 275, 334-343.

32. Britten, R.; Davidson, E. Gene regulation for higher cells: A theory. Science 1969, 165, 349-357. 
33. Materna, S.C.; Davidson, E.H. Logic of gene regulatory networks. Curr. Opin. Biotechnol. 2007, 18, 351-354.

34. Ibarra, R.U.; Edwards, J.S.; Palsson, B.O. Escherichia coli K-12 undergoes adaptive evolution to achieve in silico predicted optimal growth. Nature 2002, 420, 186-189.

35. Fong, S.S.; Marciniak, J.Y.; Palsson, B.O. Description and interpretation of adaptive evolution of Escherichia coli K-12 MG1655 using a genome-scale in silico metabolic model. J. Bacteriol. 2003, 185, 6400-6408.

36. Teusink, B.; Wiersma, A.; Jacobs, L.; Notebaart, R.A.; Smid, E.J. Understanding the adaptive growth strategy of lactobacillus plantarum by in silico optimization. PLoS Comput. Biol. 2009, 5, e1000410.

37. Unrean, P.; Srienc, F. Metabolic networks evolve towards states of maximum entropy production. Metab. Eng. 2011, 13, 666-673.

38. Dincer, I.; Cengel, Y.A. Energy, entropy and exergy concepts and their roles in thermal engineering. Entropy 2001, 3, 116-149.

39. Lucia, U. Irreversibility entropy variation and the problem of the trend to equilibrium. Physics A 2007, 376, 289-292.

40. Lucia, U. Exergy flows as bases of constructal law. Physics A 2013, 392, 6284-6287.

41. Bejan, A. Shape and Structure, from Engineering to Nature; Cambridge University Press: Cambridge, UK, 2000.

42. Bejan, A. Entropy Generation through Heat and Mass Fluid Flow; Wiley \& Sons: New York, NY, USA, 1982.

43. Bejan, A. Entropy Generation Minimization; CRC Press: Baca Raton, FL, USA, 1995.

44. Bejan, A.; Tsatsatronis, A.; Moran, M. Thermal Design and Optimization; Wiley \& Sons: New York, NY, USA, 1996.

45. Bejan, A.; Lorente, S. The constructal law and the thermodynamics of flow systems with configuration. Int. J. Heat Mass Transf. 2004, 47, 3203-3214.

46. Bejan, A.; Lorente, S. The constructal law of design and evolution in nature. Philos. Trans. R. Soc. B 2010, $365,1335-1347$.

47. Bejan, A. Advanced Engineering Thermodynamics; Wiley \& Sons: New York, NY, USA, 2006.

48. Annila, A.; Salthe, S. Physical foundations of evolutionary theory. J. Non-Equilib. Thermodyn. 2010, 35, $301-321$.

49. Grönholm, T.; Annila, A. Natural distribution. Math. Biosci. 2007, 210, 659-667.

50. Kaila, V.R.I.; Annila, A. Natural selection for least action. Proc. R. Soc. A 2009, 464, 3055-3070.

51. Annila, A. The 2nd law of thermodynamics delineates dispersal of energy. Int. Rev. Phys. 2010, 4, $29-34$.

52. Lucia, U. Maximum or minimum entropy generation for open systems? Physics A 2012, 392, 3392-3398.

53. Lucia, U. Considerations on non equilibrium thermodynamics of interactions. Physics A 2016, 447, 314-319.

54. Lucia, U. Thermodynamic paths and stochastic order in open systems. Physics A 2013, 392, 3912-3919.

55. Nicolis, B.G.; Prigogine, I. Self-Organization in Nonequilibrium System; Wiley Interscience: New York, NY, USA, 1977.

56. Glansdorff, P.; Prigogine, I. Thermodynamic Theory of Structure, Stability and Fluctuations; Wiley Interscience: New York, NY, USA, 1978.

57. Lucia, U. Entropy generation approach to cell systems. Physics A 2014, 406, 1-11.

58. Lucia, U. Bioengineering thermodynamics: An engineering science for thermodynamics of biosystems. Int. J. Thermodyn. 2015, 18, 254-265.

59. Lucia, U. Bioengineering thermodynamics of biological cells. Theor. Biol. Med. Model. 2015, 12, doi:10.1186/s12976-015-0024-z.

60. Lucia, U.; Sciubba, E. From Lotka to the entropy generation approach. Physics A 2013, 392, 3634-3639.

61. Lucia, U. Electromagnetic waves and living cells: A kinetic thermodynamic approach. Physics A 2016, 461, 577-585.

62. Lucia, U.; Grisolia, G. Second law efficiency for living cells. Front. Biosci. 2017, 9, $270-275$.

63. Lucia, U. Thermodynamic approach to nano-properties of cell membrane. Physics A 2014, 407, $185-191$.

64. Albarrán-Zavala, E.; Angulo-Brown, F. A Simple Thermodynamic Analysis of Photosynthesis. Entropy 2007, 9, 152-168.

65. Andriesse, C.D.; Hollestelle, M.J. Minimum entropy production in photosunthesis. Biophys. Chem. 2001, 90, 249-253.

66. Lucia, U. Entropy and exergy in irreversible renewable energy systems. Renew. Sustain. Energy Rev. 2013, 20, 559-564.

67. Mata, T.M.; Martins, A.A.; Caetano, N.S. Microalgae for biodiesel production and other applications: A review. Renew. Sustain. Energy Rev. 2010, 14, 217-232. 
68. Singh, S.P.; Singh, P. Effect of $\mathrm{CO}_{2}$ concentration on algal growth: A review. Renew. Sustain. Energy Rev. 2014, 38, 172-179.

69. EUROSTAT. 2017. Available online: ec.europa.eu/eurostat/statistics-explained/index.php/Electricity_ price_statistics (accessed on 8 October 2017).

70. Toman, M.; Jemelkova, B. Energy and economic development: An assessment of the state of knowledge. Energy J. 2003, 24, 93-112.

71. Stern, D.I. Energy quality. Ecol. Econ. 2010, 69, 1471-1478.

72. Borowitzka, M.A.; Borowitzka, L.J. Micro-Algal Biotechnology; Cambridge University Press: Cambridge, UK, 1998.

73. Huber, G.W.; Iborra, S.; Corma, A. Synthesis of Transportiation Fuels from Biomass: Chemistry, Catalysis, and Engineering. Chem. Rev. 2006, 106, 4044-4098.

74. Ragauskas, A.J.; Williams, C.K.; Davison, B.H.; Britovsek, G.; Cairney, J.; Eckert, C.A.; Frederick, W.J.J.; Hallett, J.P.; Leak, D.J.; Liotta, C.L.; et al. The path forward for biofuels and biomaterials. Science 2006, 311, 484-489.

75. Alzate, C.A.C.; Toro, O.S. Energy consumption analysis of integrated flowsheets for production of fuel ethanol from lignocellulosic biomass. Energy 2006, 31, 2447-2459.

76. Piccolo, C.; Bezzo, F. A techno-economic comparison between two technologies for bioethanol production from lignocellulose. Biomass Bioenergy 2009, 33, 478-491.

77. Brandt, A.R. Oil Depletion and the Energy Efficiency of Oil Production: The Case of California. Sustainability 2011, 3, 1833-1854.

78. Dincer, I.; Rosen, M.A. A worldwide perspective on energy, environment and sustainable development. Int. J. Energy Res. 1998, 22, 1305-1322.

79. Hammond, G.P. Towards sustainability: Energy efficiency, thermodynamics analysis, and the 'two cultures'. Energy Policy 2004, 32, 1789-1798.

80. Lu, X. A perspective: Photosynthetic production of fatty acid-based biofuels in genetically engineered cyanobacteria. Biotechnol. Adv. 2010, 28, 742-746.

(C) 2018 by the authors. Licensee MDPI, Basel, Switzerland. This article is an open access article distributed under the terms and conditions of the Creative Commons Attribution (CC BY) license (http:/ / creativecommons.org/licenses/by/4.0/). 